International Journal of Linguistics, Literature and Culture
Available online at https://sloap.org/journals/index.php/ijllc/
Vol. 6, No. 4, July 2020, pages: 76-87
ISSN: 2455-8028
https://doi.org/10.21744/ijllc.v6n4.907

\title{
Deconstructing bond of signifier $\&$ signified: a corpus-based study of variation in meaning
}

Marghoob Ahmad a

Article history:

Submitted: 18 April 2020

Accepted: 09 May 2020

\section{Keywords:}

deconstruction;

meanings' variation;

signified;

signifier;

\begin{abstract}
The study aimed at investigating a bond between the signifier and signified to explore and develop an in-depth understanding of meanings' variation, by setting qualitative paradigm, textual examples were marked from text corpora and linguistic signifiers, believed to be representing the text were serialized using judgmental sampling. The key informant happened to be a text (The Reluctant Fundamentalist) taken as a unit of study, with the approach of Derrida's deconstruction, signifiers were decoded and then qualitatively analyzed in terms of binary oppositions to mark variation in meaning. It resulted that words were not intrinsically meaningful but just types of sound or mark being meaningless in itself and they gave meaning by playing a role in something we did with them. The outcome of the whole endeavor was a play of meaning continued endlessly in connection with signifier and signified from one context to another. Stable meaning appeared to be a hopelessly unsuitable task in a text and with the contextual shift, it stood unnaturalized. The usefulness of analyzing text was adequate preparation for teaching turning contents into skill-oriented tasks and the process of meanings' variation between signifier and signified widened the scope of developing Content Specification Charts concerning learners' needs.
\end{abstract}

International journal of linguistics, literature and culture (c) 2020. This is an open access article under the CC BY-NC-ND license. Peer-review under responsibility of International Association for

Technology, Education and Language Studies (IATELS) (https://creativecommons.org/licenses/by-nc-nd/4.0/).

\section{Corresponding author:}

Marghoob Ahmad,

Department of English, Islamia University Bahawalpur, Pakistan.

Email address: marghoob.hmd@gmail.com

${ }^{a}$ Department of English, Islamia University Bahawalpur, Pakistan 


\section{Introduction}

A sign was made of a concept and sound-image deputed for signifier and signified both were formed with an associative bond in the human brain making a psychological imprint on it. It engrossed significant place in human life which was an originator of expressing a thought by referring to some object of living (Beaney, 1997). The foreplay of a signifier was not fixed to a signified but pointed out beyond itself to another signifier made up equally in the endless interaction of differences. The signified was the concept, meaning, and thing indicated by the signifier, not the real object but some referent to which the signifier referred, and the thing signified was created in the perceiver internal to him (Bradley, 1930). For Saussure, the root concept was malleable and the signifier reflected the signified and the former created the later in terms of meaning triggered for us.

The meaning of sign needed the two as created by an interpreter, one was merely a noise without another, one was impossible without another. Words had meaning in different and even in relationships with other words when we thought in words and images, these still signified something not to be the final signified appearing as a more abstract sensation and the external signified could neither be truly known (Austin, 1962). Both signifiers and signified were stable only if one term was incapable of referring beyond itself not to be true and the meaning was deferred when sliding between signs (Brown, 2005). Frege tossed with Locke's significant assumptions that the nature of language was to be defined by its functions.

Meanings were created by the help of interpreting a signifier which had no meaning if separated from signified, the concept horse was not an object being referent of a predicate, this, in turn, threatened the distinction between concept and object because same creatures had hearts as well kidneys, the predicate $\mathrm{x}$ has a heart, and a kidney to be true of just the same things, meaning thereby they possessed the same referents but again it was absurd to think that they had the same meanings.

Moreover, there could be two names for the same mountain. One was associated with its varied look from the South; the other was with its appearance from the North. Gold referred to gold as metal but it expressed the sense of gold by which the metal was presented to us, if the name did not refer to any real thing then it had no reference. If the name did not possess reference then the sentence as a whole had no reference, a thing could contain a sense without some reference. This sentence as a whole expressed thought even though it had no truth-value because the morning star and evening star referred to the same thing (Bass, 1978). According to Frege, if different people had various ways of picking out the same object then they would associate a different sense with any name of that object and words referred to things in the real world only indirectly standing for ideas directly, the condition could exist even if no object met it, words referred to their referents only indirectly and the meanings of words were concerned with things in the world rather than things in the mind, we could expect two words associated with the same thing if a word was not associated with anything in the world then it had no meaning.

According to Derrida, the stable meaning was a hopeless task in a text one after another reading meaning did not remain natural and inevitably adulterated even it also repudiated any single correct meaning of a text and no text could fetch a single reliable meaning to any reader. It peeked at the text on the whole and what holes laid in between it what was said and what was left unsaid and incidental features of a text were also seen betraying its quintessential meaning. The text was to be decoded from inside and outside because of the rapidly shifting nature of language, there were only temporary truths in the textual interpretation and we could not limit the meaning of words in a given text.

Derrida prosecuted an absence of meaning that words possessed with them no definite meanings if each word was a sign having a signifier and a signified then later also acted as former then which meaning was to be taken in the text (Bach, 1987). The function of deconstructionism was to show how a critic decoded text by questioning the non-judgmental character of dichotomies which were faced with like legitimate or illegitimate, good and bad, etc. A gesture, a book, and a text could also be decoded, with this the primary conception of text was widened.

\section{Literature Review}

\subsection{Levels of sign}

From Parmenides in the fifth century BC and Roman writers as Cicero and Quintilian, all had employed the term sign to mean evidence, proof, or symptom of what is temporarily hidden from view, for instance, the smoke was a sign of fire and clouds were a sign of an impending storm for the sailor at sea and a flushed complexion was also a

Ahmad, M. (2020). Deconstructing bond of signifier \& signified: a corpus-based study of variation in meaning. International Journal of Linguistics, Literature and Culture, 6(4), 76-87. https://doi.org/10.21744/ijllc.v6n4.907 
sign of fever for the physician. It was also employed in the sense of a sign or omen of the supernatural and also used to stand for facial expressions or behavioral signs of mental states themselves inaccessible to the observer as blushing were a sign of shame but the paradigm sign was the medical symptom as mean to diagnose the condition of a patient.

The principle for classical philosophers was a physician who sought a hidden disease to cure it, for Hippocrates a woman giving birth was a sign of past sexual intercourse with the inference from sign to what was signified going from effect to prior cause while a serious wound was the sign of death with the inference now from a presently observed cause to a future effect. Classical writers had distinguished Aristotle's necessary signs from probabilistic signs not guaranteed the presence of what they signified. Epicureans held a sign as a sensible particular which was an object of direct observation rather than a proposition expressed as an inference. Illiterates and lower animals were incapable of reasoning and interpreting signs. Sweating a lot could be interpreted as a sign of invisible pores on the skin and the behavior of a person was a sign of motion in the soul. A woman giving milk was a sign of bearing a child (Clarke, 1987). Stoics included conventional signs like a torch signifying an approaching enemy and bell was signifying the selling of meat, these signs were determined by lawgivers and they were in our power whether we made to be known one thing or to be significant by many things (Chandler, 2002).

However, verbal utterances were also included within the class of signs similarly, facial expressions were regarded as signs of mental states, a person's laughter was a sign of joy and a scream of fear, utterances of indicative sentences such as 'it was raining' could be regarded as a basis for inferring the speaker's belief and utterances of 'close the door' for inferring his desire for the door to be closed.

\subsection{Signifier \& Signified}

Saussure's terms signifier and signified were employed indicating two faces of the sign, the signifier was sound structure ordained not by the immediate sound of a particular pronunciation in a material sense but by its identifying features of similarity from other sound structures in its language (Chomsky, 2000) and the signified was a meaning complex not determined by the immediate burden of a particular usage but it was viewed by patterns of contrast which one word had established with other words in its language. The subsequent classification of signs as indexes, icons, and symbols according to the relationship between signifier and object has been widely adopted in semiotic literature (Chomsky, 1965), the signifier was auditory unfolded solely in time, and in contrast to visual signifiers, auditory signifiers had at their command only the dimension of time, their elements were presented in succession and they formed a chain. A signifier could be sensed by the mind and natural signifiers made us aware of something beyond them. Augustine demonstrated the link between natural signs and evidential signs (Morris, 2007). Ockham explicitly rejected the view that the spoken word signified the mental concept or passion of the soul. It signified independent objects which the mental word signifies. The conceived term was an intention or passion of soul which by its nature signified or co-signifies something.

\subsection{Mutability\& Arbitrariness}

The signifier was fixed in terms of linguistic community and it was not changeable easily if it was established in a linguistic community. A particular state of language was always the product of historical forces, and these forces explained why the sign was unchangeable why it resisted any arbitrary substitution of why the historical factor of transmission dominated entirely which prohibited any sudden widespread change (Gibson, 2004). The signifier could change not only in its material aspect but also in its grammatical form. Mutability was so inescapable that it even held for artificial languages. A meaning of a lexical unit was distinguished in a dictionary from other meanings. Thus, the chair had one sense when it was used to refer to a piece of furniture and another when used to refer to someone chairing a meeting. The chair was defined by the relations that distinguished it from furniture, from the armchair, from the table, and so on, the meaning of expression was different from its reference. The bond between the signifier and signified was arbitrary because a sign designated the whole that resulted from the associating of the signifier with the signified. The word arbitrary did not imply that the choice of the signifier was left entirely to the speaker. The individual did not have the power to change a sign in any way if once it had been established by a linguistic community (Hacker, 2001). The arbitrary nature of the sign protected language from any attempt to modify it but a language was a system of arbitrary signs, the signifier was treated by its users as something which stood for the signified. 
Saussurean semioticians emphasized that there was no inevitable relationship between signifier and signified. He stressed on the arbitrariness of the sign by specifying the link between the signifier and the signified (Hacking, 1975). For Saussure, the arbitrary nature of the sign was the first principle of language, and there was no inherent connection between signifier and signified (Hacker, 2001). The principle of arbitrariness was not an original conception. Aristotle had noted that there could be no natural connection between the sound of any language and the things signified. Whatever name you give to a thing was its right name and if you gave up that name and change it for another, the latter name was no less correct than the earlier just as we changed the name of our servants.

\subsection{Form, sense \& object}

Peirce offered a triadic mode in which the traffic sign for stop consisted of light facing traffic at an intersection. A red light indicated that vehicles must stop at an intersection. This model of the sign included an object or referent which did not feature directly in Saussure's signifier while the interpretant was similar in meaning to the signified, the interpretant had a quality unlike that of the signified and it was a sign in the minds of the interpreter. Peirce had noted that a sign addressed somebody by creating in the mind of a person an equivalent sign. A signified could itself play the role of a signifier if we employed a dictionary to look up yet another word used for the same word. This concept went beyond Saussure who emphasized the value of a sign in its relation to other signs and it was developed more radically by post-structuralist theories. Peirce viewed that all thinking was dialogic in form. This notion resurfaced in a more developed form in the 1920s in the theories of Mikhail Bakhtin.

However, if a signifier was constrained by the signified then the sign was motivated in an iconic sign (Bradley, 1930). Guy Cook, the British linguist, asked whether the iconic sign on the door of a public lavatory for men looked more like a man than like a woman. A sign was truly iconic; it had to be transparent for someone who had not seen it beforehand when we already know the meaning then we go for its resemblance.

Besides, if pieces made of ivory were substituted for pieces made of wood, then the change made no difference to the system (Forster, 2004). Paris train was referred to as the same train even though the combinations of locomotive or carriages might be changed, he asked that if a street was completely rebuilt then it could still be the same street. Saussure insisted that such entities were abstract which could conceive of a street or train outside of its material realization.

Similarly, if the word man occurred hundreds of times in a book of which myriads of copies were printed, all those millions of triplets of patches of ink were embodiments of the same word each of those embodiments a replica of the symbol. This showed that the word was not a thing. Peirce did allude to the materiality of the sign because all signs had concrete material reality and the physical properties of the sign played an important role in language.

The psychoanalytic theory also contributed to the revaluation of the signifier and in Freudian theory, the sound of the signifier might be articulated as a better guide to its possible signified than any conventional decoding. Poststructuralist theorists had sought to revalorize the signifier on the whole (Stern, 2004). The phonocentrism allied with Saussure's suppression of the materiality of the linguistic sign was challenged in 1967 when the French poststructuralist Jacques Derrida, in his "Grammatology" had attacked the privileging of speech over writing which was found in Saussure.

\subsection{Dualism of Form and Content}

The distinction between signifier and signified had been equated to the dualism of form and content. The signifier was seen as the form of the sign and the signified as the content. The metaphor of form as a container was problematic tending to support the equation of content with meanings. The meaning could be sucked without an active process of interpretation and form was not in itself meaningful (Chandler, 2002). There could be no content without an expression both expression and content had substance and form. There were four categories like the substance of expression, a form of expression, substance of content, and form of content. Saussure had insisted that language was a form, not a substance.

Hjelmslev's framework allowed us to analyze texts according to their various dimensions and to grant each of these the potential for signification. Words simply mirror objects in an external world. Words were only names for things and things necessarily existed independently of language before them being labeled with words. While each leaf, cloud, or smile was different from all others. The signified was only a mental concept but not an external object. (Bradley, 1930) A concept might refer to something in experiential reality but the Saussurean stance was a denial of the essentialist argument that signifieds were autonomous entities in an objective world that were definable in terms

Ahmad, M. (2020). Deconstructing bond of signifier \& signified: a corpus-based study of variation in meaning. International Journal of Linguistics, Literature and Culture, 6(4), 76-87. https://doi.org/10.21744/ijllc.v6n4.907 
of some kind of unchanging essence. Saussurean semiotics asserted the non-essential nature of objects. Just like signifiers, signifieds were part of the sign-system which were socially constructed. The signified was an arbitrary product of our culture's way of seeing things.

So, the power of language systems was that there was a great difference between the signifier and signified (Stern, 2004). In the middle ages, words and images were still seen as having a natural connection to things. Words were seen as the names of things rather than representations. Michel Foucault had shown that in the early modern period, scholars came to see words and other signifiers as representations which were subject to conventions rather than copies. By the seventeenth century, the distinctions had been made between ideas and things. Scholars had regarded signifiers as referring to ideas rather than things, such signifiers meant different things to different people and they might stand for many things. Saussure had seen the signifier and the signified inseparable which were two sides of a piece of paper. Poststructuralists had rejected the stable and predictable relationship embedded in his model. The French Psychoanalyst Jacques Lacan had written off the incessant sliding of the signified under the signifier. There could be no anchoring of a particular signifier to a particular signified.

Jacques Derrida reared to the foreplay of signifiers not fixed to their signified but they pointed out beyond themselves to other signifiers in an infinite way. Derrida championed the deconstruction of the western semiotic system by denying any determinable meanings. For Saussure, the meaning of signs derived from how they differed from each other. Derrida had coined the term difference to allude also to how meaning was endlessly deferred. For Marxists and realists, postmodernist idealism was intolerable and signs could not be permitted to swallow up their referents in a never-ending chain of signification. In the post-modern age of hyper-reality in which what were only illusions in the media of communication seemed to be very real and signs hid the absence of reality which pretended to mean something. There was still a direct link between signifiers and their signifieds when signifiers came to stand in relation only to other signifiers and not about any fixed external reality. The relationship between signifiers and their signifieds might be ontologically arbitrary but they were not socially arbitrary.

\subsection{Deconstruction tasks}

The task of deconstruction was to identify the connection between text and meaning. The language was viewed as a system of signs and words only possessed meaning concerning the contrast between these signs and meaning was never present but rather was deferred to other signs. Derrida referred to a self-sufficient and non-deferred meaning which was a metaphysical presence of a sign. A concept must be understood in the context of its opposite on the whole and gave us the meaning of an actual signifier. Derrida argued that deconstruction needed to create new terms and not to synthesize the concepts in opposition (Clark, 1987). It was bent upon marking their differences and eternal interplay. The word deconstruction was a concept from the work of Martin Heidegger that Derrida had sought to apply in textual reading. Heidegger's term had referred to a process of exploring the categories and concepts which tradition had imposed on a word and the history behind them. Derrida opted for deconstruction over the literal translation to suggest precision rather than violence. Derrida's concerns flowed from a consideration of several issues. It was a desire to contribute to the re-valuation of all western values which were built on the $18^{\text {th }}$ century Kantian critique of reason. It was carried forward to the $19^{\text {th }}$ century in its more radical implications by Kierkegaard and Nietzsche. Texts outlived their authors and became part of a set of cultural habits equal to the importance of authorial intent.

\subsection{Idea of difference}

The difference was a significant idea within deconstruction and meanings of words came from their synchronic existence with other words within the language and their diachronic placement between contemporary and historical definitions of a word. According to Derrida, this required an understanding of both viewpoints of linguistic analysis. The focus on diachrony had led to accusations against Derrida of engaging in the Etymological fallacy. There was one statement by Derrida which had been of great interest "there was no outside-text" which was often mistranslated as "there was nothing outside of the text". The mistranslation was often used to suggest Derrida's beliefs that nothing existed but words.

According to Derrida, his statement simply referred to the unavoidability of context that was at the heart of the difference. For instance, the word "house" derived its meaning more as a function of how it differed from "shed", "mansion", "hotel", "building", than how the word "house" might be tied to a certain image of a traditional house. Could we talk about a "house" or a "mansion" or a "shed"? The same could be said about verbs in all the languages 
in the world. When should we stop saying "walk" and start saying "run"? The differences between words were relevant here (Brown, 2005). Thus, the complete meaning was always "differential" and postponed in language. There was never a moment when meaning was complete and total. A simple example would consist of looking up a given word in a dictionary by proceeding to look up the definitions of the word, and if we compared the same word in older dictionaries from different periods in time then such a process of generating new meanings would never end.

\subsection{Binary oppositions}

Derrida described that the task of deconstruction was to identify the metaphysical elements of the present entity like signs. Metaphysics of presence was the desire for immediate access to meaning and the privileging of presence over absence. This meant that there was an assumed bias in certain binary oppositions where one side was placed in a position of another such as good over bad, speech over the written word, male over female among other oppositions (Halliday, 2014). Deconstruction targeted to find out the meaning in a given text by exposing the supposed contradictions and internal oppositions. Those foundations were irreducibly complex, unstable, or impossible. Any text was not a discrete whole but contained several irreconcilable and contradictory meanings, it had more than one interpretation and the text itself linked these interpretations inextricably. The incompatibility of these interpretations was irreducible and an interpretative reading could not go beyond a certain point. The meaning is made possible by the relations of a word to other words within the network of structures (Derrida, 1982). Structuralism had viewed language as a system of signs composed of a signified and a signifier. Derrida had proposed that signs always had referred to other signs by existing only to each other and there was no ultimate foundation or center which was the basis of difference.

Deconstruction was not a dismantling of the structure of a text but it was a demonstration that it had already dismantled itself. Its solid ground was no rock but thin air. It examined the internal logic of any given text or discourse by helping many authors to analyze the contradictions inherent in all schools of thought. Since Hegelianism believed that binary oppositions would produce a synthesis while Derrida saw binary oppositions as incapable of collapsing into a synthesis free from the original contradiction.

In Derridian notion, deconstruction was an "anti-structuralist gesture" because structures were to be decomposed. For Derrida, deconstruction was also a "structuralist gesture" because it was concerned with the structure of texts (Brown, 2005). An example of structure would be a binary opposition such as good and evil where the meaning of each element was established, at least partly, through its relationship to the other element. A linguistic system was a series of differences of sound which were combined with a series of differences of ideas. But the pairing of a certain number of acoustical signs with as many cuts made from the thought engendered a system of values.

\subsection{Meaning proliferation}

The fundamental aim of deconstructionism was to establish any secure meaning in a text. Words refer to other words by attempting to demonstrate how statements about any text subvert their meanings. Derrida's particular methods of textual criticism involve discovering, recognizing, and understanding of the text. The distinction between what is inside the text and what is outside can itself be deconstructed. According to the same principles, deconstruction is a historicizing movement that opens the texts to the conditions of their production and their context in a very broad sense (Hacker, 2001). It also includes not only the historical circumstances and tradition from which the texts arose but also the conventions of the language in which they are written and the details of their author's live. This generates an effectively infinite complexity in texts that makes any deconstructive reading necessarily partial and preliminary.

Deconstruction is always an on-going process because of the constantly shifting nature of language, no final meaning or interpretation of a text is possible (Stern, 2004). The basic strategy is still to follow the blind spot through the text to illuminate hierarchical oppositions. The fault lines in structures are to be deconstructed in the text. Gadamer speaks of the debate as one between Heidegger's reading of Nietzsche and Derrida calling deconstruction a repudiation of the language of concepts, and it is the legacy of European philosophy and deconstruction is always a question of debt to the texts.

Deconstruction has attacked the assumption that these structures of meaning are stable, universal, and historical, the emphasis of deconstruction on the proliferation of meanings is related to the concept of iterability. Iterability is the capacity of signs to be repeated in new situations and grafted onto new contexts (Stern, 2004). Derrida's aphorism "iterability alters" meant that the insertion of texts into new contexts continually produced new meanings

Ahmad, M. (2020). Deconstructing bond of signifier \& signified: a corpus-based study of variation in meaning. International Journal of Linguistics, Literature and Culture, 6(4), 76-87. https://doi.org/10.21744/ijllc.v6n4.907 
that were both partly different from and partly similar to previous understandings. The term "Play" was sometimes used to describe the resulting instability in meaning produced by iterability. Our understanding of a word depends on other words with an endless chain of signifiers by pointing to nothing beyond themselves and developing out a history of usage which is entirely lost to us (Stern, 2004). But signifiers defer to each other, and they may leave a trace of their deferments where the author of the text in question has suppressed meaning by choosing one word in preference to another. The author exercises his authority in selecting his signifiers. It may not be truly manifested by the use of words. The inner intention of the author cannot be a point of determining final meanings in a text. The text can be the product of repeated suppressions of other thoughts. Meaning is not something pre-existing in the mind that we struggle to express by composing a text.

From Hume onwards, Derrida, contrary to Saussure does not regard words as the expression of ideas and his second tenet is words that rest on nothing on speech, intention, naming, deep grammar, metalanguage, and social usage. We cannot define a word except concerning other words, and these, in turn, call on other words. Analytical philosophers exercise to find out meaning, truth, and belief in texts, and Derrida studied some of them. But analytical philosophy he sees as much too narrow and self-centered.

Derrida's mission is to show that texts, institutions, traditions, societies, beliefs, and practices do not have definable meanings, and will always exceed the boundaries they currently occupy. Deconstruction has become a method of reading a text and reading was to be a free, joyous, and creative performance. The sign was at the beginning and without it, we can never arrive at the meaning independently in any text. We must pass before canceling it out as unwanted rhetoric. According to structuralism, there was nothing outside the structure. A signifier always had a signified being related in the same way that the sensible was related to the intelligible. One was visible while the other was invisible. The sign, in other words, was always reduced to the content it signified.

Deconstruction was a critical viewpoint to check the relation between text and meaning. Words possessed meaning because of contrast-effects with other words. No word could get meaning in the way by which philosophers from Aristotle to Bertrand Russell had hoped to capture it. It was an unmediated expression of an object, an idea, and a platonic form, etc. The meaning was never present but deferred to other signs. The non-deferred meaning was called metaphysics of presence. For example, being was a binary opposition of nothingness. The word "Being" was a present signifier, but the sign "Nothingness" was its metaphysics of presence. Deconstruction needed to create new terms, and it did not synthesize the concepts in opposition. It was to mark their difference and eternal interplay. Derrida had taken the concept of deconstruction from Martian Heidegger which was applied as a tool for textual reading. We were driven by a desire to make meanings (Hacker, 2001). We were surely meaning-makers. Distinctively, we made meanings through our creation and interpretation of signs by taking the form of words, images, sounds, flavors, acts, and objects but such things had no intrinsic meaning and became signs only when we invested them with meanings. Nothing was a sign unless it was interpreted as a sign. Anything could be a sign as long as someone interpreted it as signifying something by referring to something other than itself. We interpreted things as signs unconsciously by relating them to familiar systems of conventions. It was this meaningful use of signs which was at the heart of the concerns of semiotics.

So, the signifier was commonly interpreted as the material form of the sign. It was something that could be seen, heard, touched, smelled, and tasted. Within the Saussurean model, the sign was the whole which resulted from the association of signifier with signified. The relationship between the two was referred to as signification (Chandler, 2004). A sign must have both a signifier and a signified. We could not have a meaningless signifier or a completely formless signified. A sign was the recognizable combination of a signifier with a particular signified. The same signifier could stand for a different signified if it was on a push-button inside a lift (Austen, 1962). Signs did not just convey meanings but constituted a medium in which meanings were constructed. The meaning was not passively absorbed but arose only in the active process of interpretation and individuals were not unconstrained in their construction of meanings.

\section{Research Problem}

The bond between the signifier and signified is arbitrary, even though deconstructionism does not establish any stable meaning operating between this relation of the two.

Objectives of the Study

1) To diagnose signifiers from selected textual examples.

2) To explore the bond between the signifier and signified.

3) To synthesize meanings' variation in narrative form. 
Research Questions

1) How is the bond between signifier and signified?

2) How is the variation in meaning between signifier and signified?

\section{Materials and Methods}

Derridian deconstructionism was set as a framework to decode signifiers from the text for that qualitative paradigm was structured to understand variation in meanings operated between signifier and signified. Data had been collected and then qualitatively analyzed from "The Reluctant Fundamentalist "taken as a unit of study, from twelve chapters of text, three textual examples were chosen from each chapter of the novel and the signifiers had been decoded from thirty-six textual examples interpreted in synthetic narration concerning relevant characters. The signifiers were identified from textual examples, and its possible three signifieds had also been analyzed by using them in other sentences. The binary opposites of signifiers were decoded too. Consequently, the variation in meanings was analyzed by employing the selected signifier in other contexts. Roadblocks had been perceived over which there had been no control of the researcher, and it is lacking a stable world in which the variation in meanings is endlessly continued from one context to another. Something might not be true about the phenomenon of study which was a foreshadowed problem.

\section{Results and Discussions}

Text analysis

\section{(Textual Example One)}

\section{“.....Do not be frightened by my beard......." (Hamid, P.1, 2007)}

Chapter one opened with Changez who was the sole narrator of the novel. He was talking to a stranger who seemed to be a journalist. Changez asked the stranger for any assistance, and he was alarmed by this saying of Changez. The stranger had been on some secret mission, and he was looking for something. Changez offered his services by telling him that he was a native of his country as well as the speaker of his language. He said to the stranger that he was a lover of America, and he might not frighten by his beard. The signifier "beard" signified terrorism in the US context, and as a cultural signifier, it was a social custom to grow a beard in Pakistan. Its binary opposition was beardless. Changez grew a beard to express his solidarity with his countrymen. But he was suspected as an ally of terrorists while working in America after the 9/11 attacks. The signifier "beard" also signified wise, fashion and terrorist. For instance, Changez's beard had frightened Americans because he seemed to be a terrorist. This type of beard could be fashion in Turkey. In this painting, Aristotle was looking wise in the beard. When deconstructed, meanings were not centered in a signifier, and the variation in meanings was markable in other sentences. With the contextual shift, the meanings of a chosen signifier were also unnaturalized.

\section{(Textual Example Two) \\ "You are hungry, and that's a good thing..." (Hamid, P.10, 2007)}

Changez told the stranger about his significant interview with Jim. During the interview, Changez remained silent, but he seemed to be annoyed. Did he ask Jim that was there any purpose for this interaction? Jim passed a smile by encouraging his temperament of asking questions. Jim told that he was from Princeton too. He had been the first man from his family to attend a college in America. He had worked in a night shift to pave his way for success. In his view, Changez was hungry. This had been a good thing in Jim's book. The signifier "Hungry" signified job, power, and food. Its binary opposite was full. For instance, a hungry man wanted only food. A politician was merely hungry for power. Changez was hungry to win a job. Meanings were decentered, when the same signifier was employed in other contexts.

\section{(Textual Example Three)}

"I hoped one day to be the dictator of an Islamic republic...." (Hamid, P.33, 2007)

Changez narrated an incident of one evening progressing the story ahead. Changez and Erica went out for dinner with the group. Erica did sit in front of Changez. When everybody was supposed to tell his dream. On his turn,

Ahmad, M. (2020). Deconstructing bond of signifier \& signified: a corpus-based study of variation in meaning. International Journal of Linguistics, Literature and Culture, 6(4), 76-87. https://doi.org/10.21744/ijllc.v6n4.907 
Changez told that he wished to become the dictator of an Islamic country with nuclear capability. Everybody was shocked and forced Changez to interpret his joke. Erica passed a smile, and she understood Changez's sense of humor. The signifier "Dictator" signified Judge, person, and actress. Its opposite was a democrat. For example; Altaf was a dictator at the party. Dr. Sonakshi was a dictator of fashion in New Delhi. An Indian Judge was working like a dictator in Delhi High Court. Meanings were decentered from one context to another if the same signifier was used in different sentences.

\section{(Textual Example Four) \\ "But I glimpse again... the crack inside her..." (Hamid, P.68, 2007)}

Changez narrated the love story of Erica and Chris. Both used to sit for hours in the park. Unfortunately, Chris had breathed his last. Changez felt the crack inside her which was visible through her trembling talk. The signifier "crack" signified bone, talk, and dawn too. Its opposite was fixed. Asad had received injury by the crack of his bone. Changez felt a crack in Erica's talk. Jim was starting his journey at crack of dawn. When decoded, the same signifier alluded to three different signifieds in cited instances by which meanings were shifted from one context to another.

\section{(Textual Example Five)}

“.....rare sneak attack or terrorist.....” (Hamid, P.144, 2007)

Changez told the stranger that he was shocked to see him here. He asked him that his country was not fighting a war on its soil. Hostile troops could, at any moment, attempt a full-scale invasion of Afghanistan after the 9/11 attacks. In the selected text, the signifier "Terrorist" signified person, freedom fighter, and fear. Its opposite was conformist. A terrorist was also a person. A terrorist was a freedom fighter too. A terrorist grew a beard to generate fear among people.

(Textual Example Six)

"I was not certain where I belonged- in New York, in Lahore, in both, in neither..." (Hamid, P.168, 2007)

Changez told about himself that he was uncertain about his belonging, and this sense of identity caused helplessness while his working in America. He had been sandwiched between New York and Lahore. He resigned from the job despite repeated warnings of Jim. Erica was no more attached to him, and she refused to accompany him when finally he planned to return Lahore. The signifier "Belonged" signified teaching, book, and club. Its binary opposite is disassociated. For instance, a man of his ability belonged in teaching. The book belonged to me. She belonged to a country club.

\section{(Textual Example Seven)}

\section{“...I was an odd sight...and hirsute Pakistani..." (Hamid, P.182, 2007)}

Changez told to a stranger that he got a job at the age of twenty-two, and this had been his first achievement. Changez described that he went to East village on foot becoming an odd sight for people. He was hirsute Pakistani carrying an unmarked box through the center of Manhattan, but he received no negative comments from the passersby. In the selected text, the signifier "Hirsute" signified person, plant, and elephant. Its opposite was "Hairless". For example, Dr. Minakshi was hirsute Hindu. This plant was covered with hirsute roots. Indian elephants were hirsute by nature.

\section{(Textual Example Eight)}

“..What is natural in one place can seem unnatural in another..." (Hamid, P.143, 2007)

Changez narrated himself that he had returned home from America. His parents had insisted on feeding him. They wished to hear in detail about his life in New York. But Changez felt it odd to speak about that world here. He said that some concepts traveled very poorly from one culture to another. Changez decided that he was not going to disclose in his family the story of Erica. He said that one thing was considered right in one culture, but the same was viewed wrong in another culture. In the selected text, the signifier "Natural" signified forest, person, and death. Its opposite was unnatural. For instance, Forests were counted in natural resources. Marwa was the natural choice for the job. The accused died a natural death.

\section{(Textual Example Nine)}

\section{“...because my own identity was fragile..." (Hamid, P.168, 2007)}

Changez told about the inner working of his mind after having been resigned from the job. He was bent upon to search for his identity by returning home. After the $9 / 11$ attacks, he was treated with an iron hand by US security agencies in New York, and this caused a patriotic feeling in him about his countrymen who had been treated discriminately across the world. Erica denied going with him in Lahore. Neither had he possessed a job nor love. His visa was going to be expired, and he was about to lose his identity. The signifier "Fragile" signified health, ego, and 
person. Its opposite was unbreakable. For instance, her health had always been very fragile. He was an artist with a fragile ego. He was in an emotionally fragile state.

\section{(Textual Example Ten) \\ "...it is our instead solitude...." (Hamid, P.176, 2007)}

Changez told that it was a man's solitude that often disturbed him. He said that we were all alone despite being in the heart of a city. In American culture, solitude could signify an abnormal behavior but in Pakistan, this cultural signifier referred to activity in Sufism for seeking spiritual pleasure. In the selected text, the signifier "Solitude" signified alone, nature and country too. Its opposite was the company. For instance, a man's solitude referred to his condition of being alone. Nature gave us a sense of solitude. No country could stand in solitude about environmental issues of the world.

\section{(Textual Example Eleven)}

"...the unthinkable is said...." (Hamid, P.179, 2007)

Changez told to a stranger the end of his love story with Erica. He asked the stranger that if he had experienced the breakup of a romantic relationship that was based on great love, then he could understand his situation what he had experienced. Changez described that in such situations; a moment of passion was developed in which the unthinkable was said. The signifier "Unthinkable" signified attack, victory, and question. Its opposite was "Thinkable". For instance, America had carried out an unthinkable attack on Afghanistan. This was an unthinkable question. Changez had completed the task by getting the unthinkable victory.

(Textual Example Twelve)

\section{"...with their harsh outlines and cramped facades..." (Hamid, P.194, 2007)}

Changez told to a stranger about plazas with their small narrow fronts which had been built largely in the eighties before the historical preservation began to take hold in Lahore. Changez described that he finds them particularly unpleasant at night. He said that these plazas mottle the surface of this area like irritation of the skin. The signifier "Facade" signified person, window, and event. Its opposite was astern. For example, there was a very nice person behind that facade of indifference. The wheel window of the main facade dated from 1274. The entire facade had troubled Catherine in this event.

\section{Conclusion}

Properties of signs were mapped with signifier and signified. No signifier was completely formless. A sign was a recognizable combination of a signifier and signified. The same signifier could stand for a different signified depending on its relations. No sign could make a sense on its own but only to other signs. Both signifier and signified proved to be purely relational entities. Signs did not just convey meanings but were constituted in a medium by which meanings were constructed.

The bond between the signifier and signified was arbitrary. A signifier referred to many signifieds from one context to another. The signified could be a concept, an object, and the thing referred by the signifier. Words were meant to be signs, and therefore, they signified the components of thought by alluding to the notion of meaning at material and metaphysical levels. A word was meant to signify something, and it's hard to see how that thing could be what the word had meant it. Words themselves had not been intrinsically meaningful, and they were just sounds that did mean nothing. One signifier might refer to many signifieds, and one signified might also be referred to by many signifiers. The signifier was seen as the form of the sign and the signified as the content.

A signifier was not fixed to its signified and it pointed out beyond themselves to other signifiers. The relationship between the two was dependent on social and cultural conventions which were needed to be comprehended. The signifier was the form in which the signified did not appear, and the signifier did not resemble the signified, and the relationship between the two was subject to change over some time. Iconic signifiers could be seen as more constrained by referential signifieds, and any fixing of the chain of signifiers was socially ordained.

The meanings of signs were concerned with the things in the world rather than things in the mind. The meanings of a word were in variation constantly which gave only temporary truth values in one context to another. It also had run at metaphysical levels away from the material world. There could not be any stable meaning of a text and it was liable to be changed in different contexts. The meaning of a sign was not contained within it but arose only through the process of interpretation. The signifier was seen as the form of the sign and the signified as the content which

Ahmad, M. (2020). Deconstructing bond of signifier \& signified: a corpus-based study of variation in meaning. International Journal of Linguistics, Literature and Culture, 6(4), 76-87. https://doi.org/10.21744/ijllc.v6n4.907 
denied any determinable meanings. The meanings of signifiers were derived from its differences. Meaning was not passively absorbed but had arisen only in the active process of interpretation. The capacity of signs was needed to be repeated in new situations.

There had not been a meaningless signifier that a sign was the recognizable combination of a signifier with a particular signified and the signifiers were related to each other within which they made sense because individuals were not constrained in their construction of meanings and words only possessed meanings concerning the contrast between signs and meanings were not present in them but were deferred to other signs. The constantly shifting nature of language meant that no final meaning or interpretation of a text as possible. Consequently, the signifier was visible but sometimes the signified was invisible or perhaps supposedly immortal.

\section{Conflict of interest statement}

The author declared that he has no competing interests.

Statement of authorship

The author has a responsibility for the conception and design of the study. The author has approved the final article.

Acknowledgments

I am grateful to two anonymous reviewers for their valuable comments on the earlier version of this paper. 


\section{References}

Austin, J. L. (1962). How to do things with words.> Cambridge, Mass. J. Austin.-Harvard University Press.

Bradley, F. H. (1930). Appearance and Reality, 9th impression.

Bouissac, P. (1967). Encyclopedia of Semiotics. Oxford University Press P.68, New York.

Brown, K. (2005). The encyclopaedia of language and linguistics.

Bass, A. (1978). Translator's introduction. Writing and difference, 1978.

Beaney, M. (Ed.). (1997). The Frege Reader (p. 259). Oxford: Blackwell.

Clarke. D (1987). Principles of Semiotics. Routledge Kegan Paul, London.

Chandler, D. (2004). Semiotics: The Basics Book.

Chapman, S., \& Routledge, C. (Eds.). (2005). Key thinkers in linguistics and the philosophy of language. Oxford University Press on Demand.

Chomsky, N. (2000). New horizons in the study of language and mind. Cambridge University Press.

Chomsky, N. (1965). Aspects of the theory of syntax (Vol. 11). MIT Press. doi, 10, 90008-5.

Derrida, J. (1982). Margins of philosophy. University of Chicago Press.

Gibson, R. F. (2004). The Cambridge Companion to Quine. Cambridge University Press.

Forster, M. N. (2009). Wittgenstein on the Arbitrariness of Grammar. Princeton University Press.

Griffiths, P. (2006). Introduction to English semantics and pragmatics. Edinburgh University Press.

Gibson, M. (2004). From Naming to Saying: The Unity of the Proposition. Oxford Blackwell.

Halliday, M. A. K. (2014). Halliday's Introduction to Functional Grammar (revised by CM IM Matthiessen, ed.).

Morris, M. (2006). An introduction to the philosophy of language. Cambridge University Press.

Stern, D. G. (2004). Wittgenstein's Philosophical investigations: an introduction (Vol. 2). Cambridge University Press.

Hacker, P.M.S (2001). Wittgenstein: A Critical Reader. Oxford: Blackwell.

Ahmad, M. (2020). Deconstructing bond of signifier \& signified: a corpus-based study of variation in meaning. International Journal of Linguistics, Literature and Culture, 6(4), 76-87. 